\title{
SOCIODRAMA COM ESTUDANTES DE ENFERMAGEM DE SAÚDE PÚBLICA
}

\author{
Maria Helena Pessini de Oliveira', Edna Paciência², \\ Flávio Fortes D'Andrea ${ }^{3}$
}

\begin{abstract}
RESUMO. O presente estudo expõe uma experiência com um grupo de estudantes do quarto ano de enfermagem, Habilitação em Saúde Pública da Escola de Enfermagem de Ribeirão PretoUSP, no qual por meio da técnica do sociodrama, procurou-se identificar as necessidades e conflitos mais freqüentes vivenciados por este grupo. Foram realizados dois grupos: grupo experimental (sociodrama) e grupo controle (verbal). Como resultado constatou-se ser o sociodrama uma técnica facilitadora da expressão de emoções suprimidas ou recalcadas, enquanto o grupo verbal tendeu a intelectualizações. Em ambos os grupos evidenciaram-se importantes temas ligados à problemática desta população, neste estágio de formação, caracterizando-a como uma população de alto risco portanto sujeita a estados de crise e conseqüentes desequilíbrios emocionais.
\end{abstract}

ABSTRACT. The authors present a experiment fulfiled with nursing fourth grade students in Public Health Habilitation. The technique used was the sociodrama through which they proposed to identify the needs and conflicts often shown by this group of university students. The population of 333 students were divided in two groups: experimental (sociodrama) and control (verbal). The results showed sociodrama confirmed as a facilitating technique for cathartic expression of suppressed or repressed emotions. The verbal group tended to intelectualizations. In both groups important themes about the problems of this population were attested. This population, because of its conflicts, may be defined as a high risk population and therefor threatened by crises and consequent emotional disturbances

\section{INTRODUÇÃO}

A motivação básica para a elaboração do trabalho que ora apresentamos surgiu de aspectos observados na vivência com estudantes. No cotidiano das atividades docentes, exercidas na formação de enfermeiros, temos observado um significativo grau de insatisfação, tensão, insegurança e mesmo reações agressivas frente aos programas de ensino e, por extensão, aos professores. A maneira liberal pela qual tem sido ministrada a disciplina de Saúde Pública na Escola de Enfermagem de Ribeirão Preto - USP, principalmente pelo uso das técnicas de discussão em pequenos grupos, tem propiciado a livre expressão de sentimentos e opiniões por parte dos alunos. Estes sentimentos e idéias são manifestados

1. Professor Assistente do Departamentn de Enfermagem Geral e Especializada da Escola de Enfermagem de Ribeirão Preto-USP. COREn-SP 5888.

2. Professor Assistente do Departamento de Enfermagem Psiquiátrica e Ciências Humanas da Escola de Enfermagem de Ribeirão Preto-USP, COREn 7265.

3. Professor Adjunto do Departamento de Neuropsiquiatria e Psicologia Médica da Faculdade de Medicina de Ribeirāo Preto-USP. 
por uma confusa preocupação com temas conflitivos, onde os temas da disciplina confundem-se com influências sócio-econômicas e políticas originadas de vivência dos estudantes que saem em campo e sentem-se impotentes para resolver problemas de ordem social. Tal fato produz um deslocamento de hostilidade para os programas de ensino, os quais julgam não corresponder às suas necessidades, estabelecendo-se assim um "jogo político" de onipotência - incompetência, envolvendo professores e estudantes. Estes criticam aqueles por não lhes darem subsídios para enfrentar os problemás que se lhes apresentam. Os estudantes são criticados por não se motivarem suficientemente nos temas de saúde e dispersarem-se em envolvimentos com temas paralelos. E claro que não se pretende minimizar as inter-relações entre saúde social e sistema social, mas as reações dos estudantes parecem traduzir-se muito mais em problemas psicológicos de quem se encontra em fase de transição.

Sabedores de que toda a observação humana está envolta em natural subjetividade e que observador e observado acabam por se confundir, não quizemos discursar sobre 0 problema sem antes procurarmos diminuir, à medida do possível, o grau de subjetividade. Entre os métodos de objetivação da observação encontramos no sociodrama, a forma ideal para abordagem sistematizada da problemática descrita, principalmente pelo fato dos estudantes já estarem acostumados com trabalhos em grupo. A literatura tem mostrado em diferentes níveis, a vantagem desta técnica na abordagem de problemas de universitários e estudantes em geral.

Em trabalhos realizados com estudantes de medicina e estudantes de enfermagem, usando técnicas dramáticas, um dos autores ${ }^{1}$ deste trabalho constatou que, basicamente, o estudante universitário vive uma "crise de identidade" que se traduz por conflitos em várias áreas, mas especificamente relacionadas com a decepção e frustração frente à própria profissão escolhida. Isto quer dizer que o grupo de estudantes fica aflito e desorientado diante das contradições da própria sociedade e cultura, onde estão inseridos.

HINSIE E CAMPBELL" definem a "crise de identidade como um conflito entre os papéis sociais percebidos pelo indivíduo; a perda do sentido de identidade pessoal e a continuidade histórica ou uma incapacidade para aceitar ou adotar o papel que a pessoa acredita que a sociedade espera dela. A crise de identidade é freqüente na adolescência e, ao apa- recer é causada por uma combinação do aumento repentino da intensidade dos impulsos com súbitas mudanças do papel social, educativo e vocacional esperado pela sociedade".

$\mathrm{O}$ método sociodramático tem por um dos seus objetivos colocar em ação em laboratório, estes sentimentos e emoções e buscar caminhos menos conflitivos para a abordagem das contradições sociais. MORENO ${ }^{3}$, seu criador, define sociodrama "como um método de pesquisa ativo e aprofundado das relações que se formam entre grupos e das ideologias coletivas. Usando técnicas dramáticas à maneira de um jogo teatral improvisado, o sociodrama realiza seus objetivos no grupo. O grupo é a personagem principal que se organiza através dos papéis sociais e modelos culturais de que são portadores os indivíduos participantes. Estes indivíduos em interação apresentam e representam seus problemas comuns. A função do sociodrama é elaborar métodos de ação em que se trabalha com instrumentos representativos de uma dada cultura em vez de simples indivíduos. Sua finalidade é resolver problemas de grupo fornecendo meios para uma catarse social...".

O sociodrama, assim, pode simultaneamente explorar e propor situações para conflitos internacionais entre setores amplos, por exemplo, educação $\mathrm{x}$ política, setores menores, como professor $\mathrm{x}$ alunos; entre valores sociais $\mathrm{e}$ culturais e mesmo entre sintomas coletivos.

Este trabalho pretendeu estudar aspectos da "crise de identidade" de uma classe de alunos cursando o quarto ano de Enfermagem, Habilitação em Saúde Pública, na Escola de Enfermagem de Ribeirão Preto, usando como instrumento o sociodrama. A premissa básica seria os alunos discutirem problemas de Saúde Pública, suas dificuldades encontradas nos estágios, os quais supúnhamos referirem-se ao relacionamento enfermeira $x$ paciente, enfermeira $x$ equipe, enfermeira $x$ comunidade. Os autores dividiram-se nas seguintes funções:

1. Coordenador dos grupos: Enfermeira psiquiátrica com treinamento psicodramático.

2. Observador participante: Enfermeira de Saúde Pública, responsável pela disciplina.

3. Supervisor: Psiquiatra. Teve como função, discutir com os demais autores, dificuldades técnicas e analisar aspectos do binômio subjetividade-objetividade.

\section{PROCEDIMENTO}

Trinta e três alunos, cursando a disciplina de Saúde Pública, foram divididos em dois grupos: "experimental" e "controle"; o pri- 
meiro composto de 22 alunos e o segundo de onze.

Grupo experimental (sociodrama) - Foram realizadas sete sessões de sociodrama de uma hora e meia de duração, obecedendo ao seguinte esquema operacional: 1 . aquecimento - 20 minutos; 2 . dramatização -40 minutos; 3. comentários e conclusões - 30 minutos.

No período de aquecimento, os estudantes eram convidados a interagir, trocando idéias até o aparecimento de um tema de interesse comum. Este tema era em seguida dramatizado, num espaço cênico onde se vivenciavam os papéis e subpapéis pertinentes ao tema. Por exemplo, se o tema fosse um incêndio, obviamente teriam que aparecer determinados papéis: vítimas, bombeiros, médicos, enfermeiras, curiosos etc. Da situação "caótica" surgiria o principal setor interacional de interesse da enfermagem. Após a dramatização o grupo discutia as emoções vividas, as contradições percebidas e as respostas estereotipadas ou renovadoras das situações.

Grupo controle (verbal) - Foram realizadas cinco sessões de uma hora e meia de duração de interação verbal, obedecendo ao seguinte esquema operacional: 1. comunicação verbal livre - 1 hora; 2. comentários e conclusões - 30 minutos.

Todas as sessões de grupo foram transcritas e sistematicamente supervisionadas. O grupo controle teve por objetivo ser um ponto de referência comparativo, uma vez que as técnicas dramáticas não são habituais em nosso meio.

\section{RESULTADOS}

Os Quadros 1 e 2 apresentam os principais dados obtidos, respectivamente, no grupo experimental e no grupo controle.

\section{ANÁLISE DOS RESULTADOS}

Comparando-se os resultados obtidos no grupo de sociodrama e no grupo de controle, observamos significativas diferenças.

No grupo de sociodrama houve uma seqüência "natural" de temas onde os aspectos interacionais tomaram adequadamente seu lugar. Os temas foram apresentados por ordem de importância tendendo a uma evolução "para o alto" (elevação de propósitos à medida que os insights iam ocorrendo e as reações pós-insight dirigiram-se da fuga para a luta), mostrando a capacidade de elaboração ideativa por parte dos membros do grupo. Os aspectos principais abordados foram relativos à própria profissão e habilitação escolhida; suas dificuldades pragmáticas e os conflitos de papéis e interpessoais advieram das dificuldades universais encontradas em todas as profissões, ocorrendo dentro de um dado sistema cultural. $O$ resultado global pode ser sintetizado numa experiência de correção emocional, onde os aspectos catárticos e introspectivos se mesclaram, levando à tendência à reconstrução e reparação, com reforço a sentimentos positivos frente ao futuro. A ansiedade paranóide foi mínima e o grupo se manteve coeso.

No grupo controle, os temas apresentaramse confusos e envoltos em prejudiciais tensões. Como as interações não eram dramatizadas, reforçaram-se as tendências defensivas de coarctação, aumentando a ansiedade. Não houve desenvolvimento de insight $\mathrm{e}$ as reações tiveram características de acting-out. Os aspectos principais referiram-se a conflitos entre áreas profissionais, principalmente à competição entre enfermeiros e assistentes sociais no campo da Saúde Pública, às dificuldades em reagir frente às pressões sociais e institucionais. O resultado global pode ser sintetizado como uma experiência de frustração, onde predominaram a confusão entre fantasia e realidade, levando ao reforço da ansiedade persecutória e pessimismo, quanto ao futuro. O grupo tendeu à não coesão.

As diferenças entre os dois grupos, em nosso entender, deveram-se predominantemente às diferentes técnicas utilizadas. No grupo de sociodrama, houve uma perfeita integração entre tempo, espaço e realidade. $O$ convite era para a ação e a experimentação de confrontos, incentivando-se os jogos de espetho e inversão de papéis. $O$ coordenador foi $e^{1}$ emento integrante no grupo. O maior número de participantes também foi uma condição favorável.

No grupo controle, a técnica aproximavase da ortodoxia analítica, isto é, valorização da comunicação verbal, posição neutra do coordenador. $\mathrm{O}$ menor número de participantes e de sessões também teve importância.

Reforçando a idéia de que, a curto prazo, a técnica sociodramática é mais eficaz, temos que considerar resultados adicionais, tais como: os estudantes do grupo sociodrama estabeleceram, a partir da experiência, um melhor relacionamento entre colegas e com os professores, mostraram maior rendimento escolar e não apresentaram intercorrências. Os do 


\begin{tabular}{|c|c|c|c|c|c|c|c|}
\hline 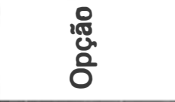 & $\underset{\mathbb{P}}{\stackrel{5}{3}}$ & $\underset{4}{\stackrel{0}{3}}$ & $\underset{4}{\stackrel{5}{3}}$ & 芳 & 苟 & 䓫 & 莺 \\
\hline 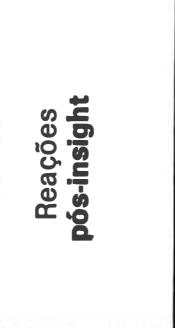 & 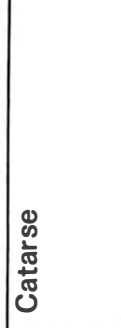 & 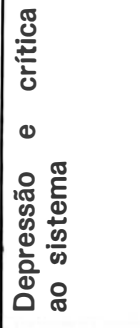 & 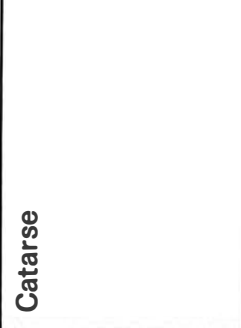 & 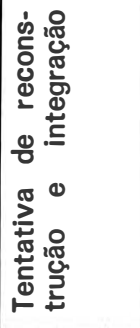 & 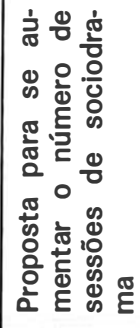 & 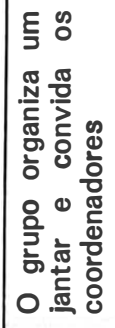 & 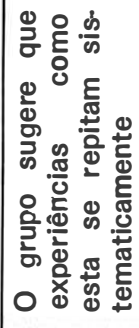 \\
\hline 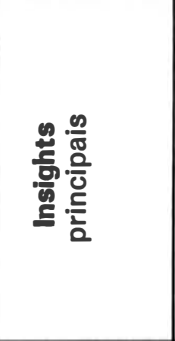 & 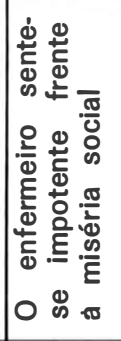 & 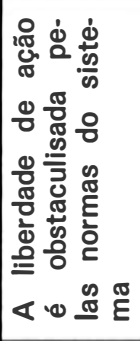 & 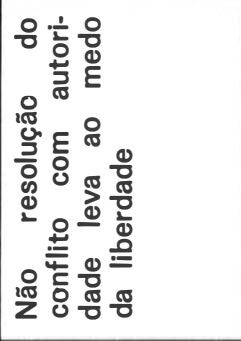 & 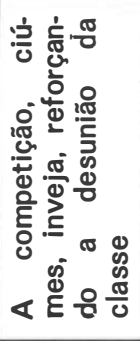 & 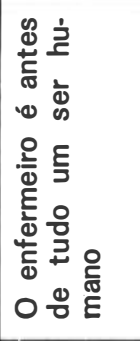 & 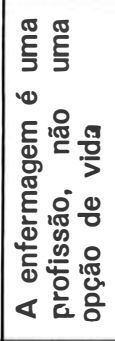 & 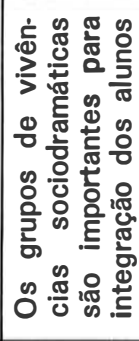 \\
\hline 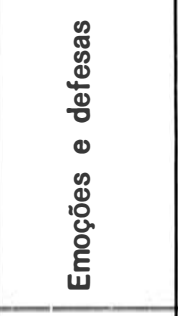 & 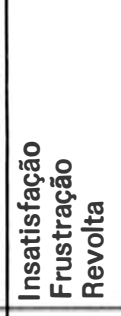 & 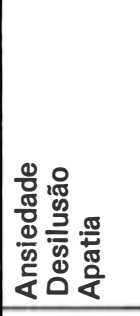 & 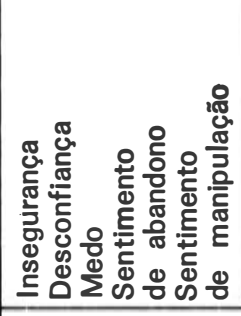 & 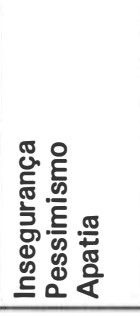 & 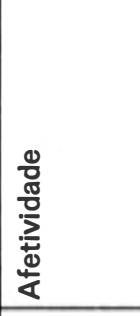 & 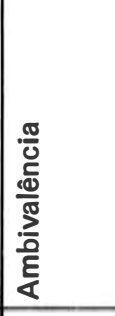 & 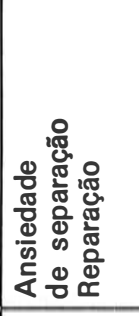 \\
\hline 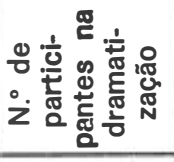 & $\theta$ & 0 & $=$ & $\stackrel{2}{2}$ & \pm & $\stackrel{0}{\circ}$ & స \\
\hline 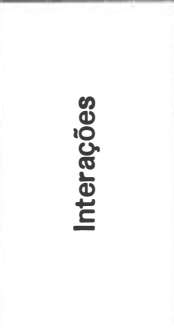 & 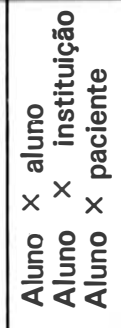 & 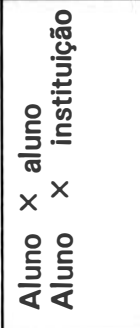 & 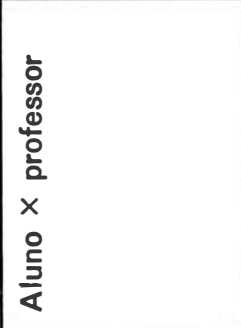 & 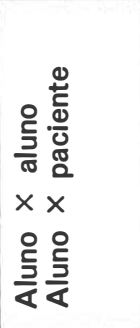 & 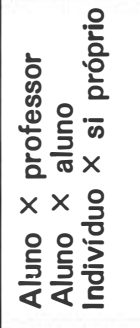 & 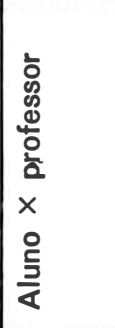 & 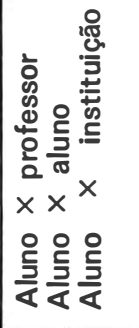 \\
\hline 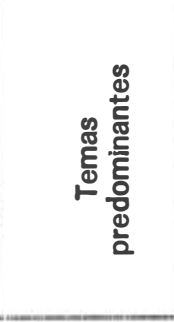 & 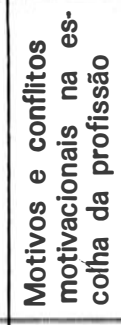 & 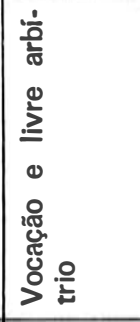 & 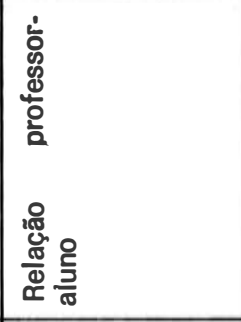 & 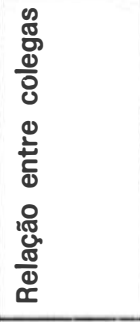 & 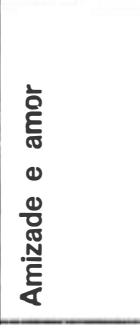 & 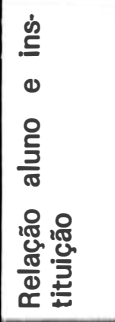 & 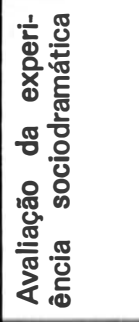 \\
\hline 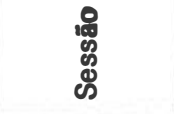 & - & $N$ & m & $\nabla$ & on & 0 & $\sim$ \\
\hline
\end{tabular}

Rev. Bras. Enf., Brasilia, 37(1), jan./fev./mar., 1984 - 47 


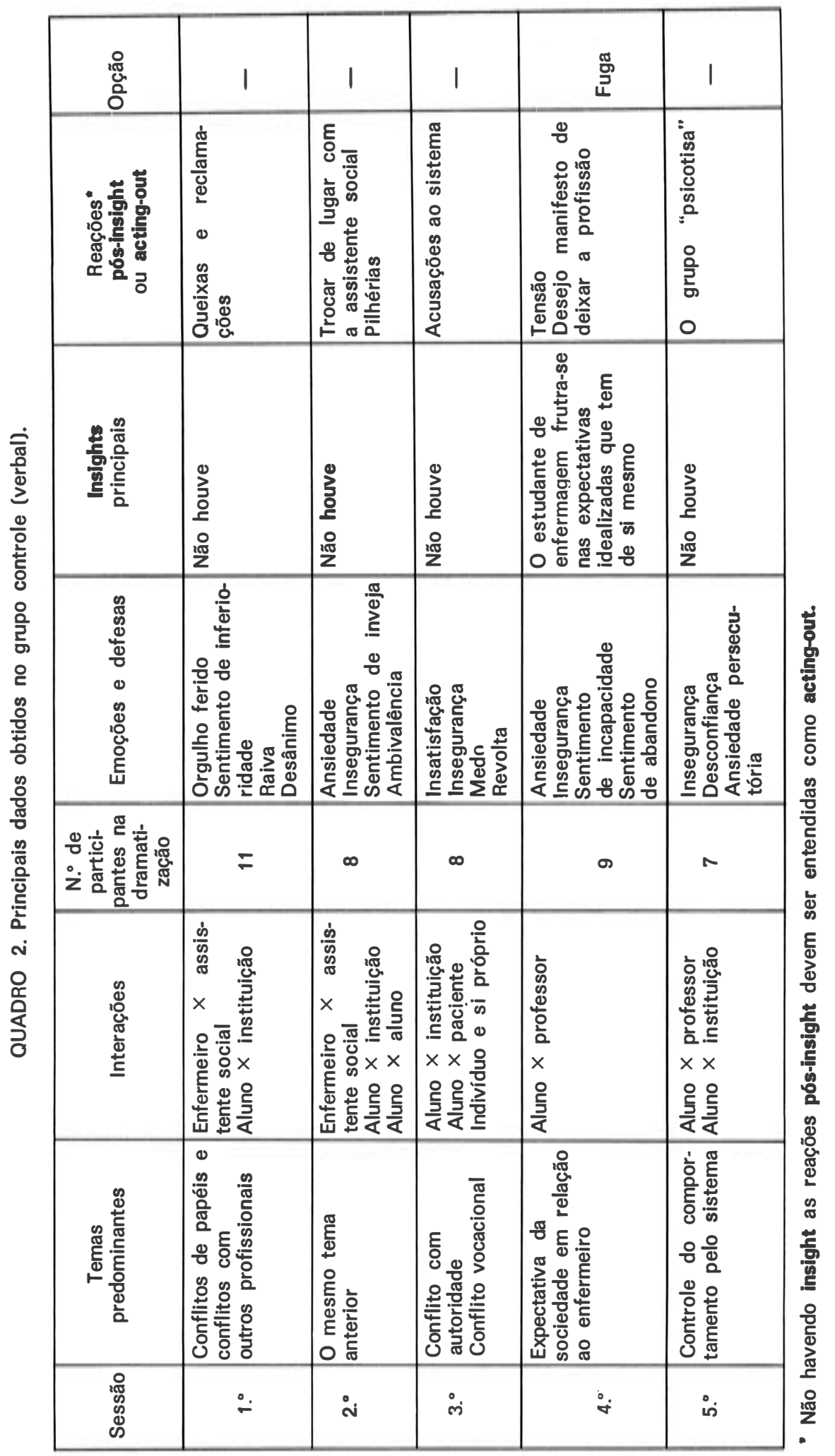


grupo controle, dispersaram-se, passaram a enxergar-se como reforço negativo, uma vez que tinham fracassado, mas apegaram-se aos professores pedindo ajuda individual, em certo sentido reforçando o esquema paternalista que tanto criticam.

Terminada a experiência, todos os estudantes receberam atenção especial e puderam ser protegidos de qualquer fixação negativa. Isto quer dizer que a busca de insight e elaboração continuou para ambos os grupos após a experiência.

\section{COMENTARIOS E CONCLUSÓES}

Além dos comentários sobre os aspectos metodológicos já expressos na análise dos resultados, cabe ainda discutir alguns aspectos temáticos.

Um dos temas discutidos em ambos os grupos diz respeito à opção pela habilitação em Saúde Pública, onde se evidencia o modo como os jovens realizam sua escolha profissional. Esta é feita por exclusão, interesse em trabalhar com a comunidade, desinteresse em trabalhar no hospital, facilidade de conciliar a vida profissional com a vida social (casamento, gravidez), etc. Desse modo, a escolha geralmente é feita muito mais por conveniência e circunstância que por interesse e vocação. Em consequiência, o grupo se sente desencorajado a prosseguir sua escolha, frustram-se diante das expectativas que não correspondem às suas reais aspirações profissionais, revoltam-se contra a estrutura social, criticando 0 sistema e tentando perverter as normas sociais.

Outro tema, o da liberdade e livre arbítrio, reflete as causas que levaram os estudantes a optarem por esta ou aquela profissão, os direitos e deveres dos estudantes, as responsabilidades sociais do profissional de enfermagem, a defasagem entre teoria e prática, bem como as contradições do sistema educacional. Sentimentos tipo decepção e defesas tipo apatia surgem e os grupos apresentam-se deprimidos.

Liberdade e competição foram dois temas muito relacionados, no qual os estudantes questionaram o espaço do profissional enfer- meiro em relação aos demais profissionais no sistema de saúde e no mercado de trabalho. Aparecem as inseguranças, o pessimismo, a desconfiança e o medo de enfrentar a realidade.

O relacionamento professor $\mathrm{x}$ aluno, professor $\mathrm{x}$ instituição, aluno $\mathrm{x}$ paciente, emerge através de queixas, reclamações, protestos e dificuldades de relacionamento com a autoridade, despertando sentimentos e fantasias persecutórias. Protestam contra o poder e se sentem impotentes frente aos seus próprios problemas, incapazes de reagir e buscar soluções eficazes para enfrentar situações emergentes. Esta impotência se reflete nas situações sociais que envolvem a atuação do profissional de saúde (impotência diante da miséria). Justificam, assim, seus pessimismos e a acomodação de alguns profissionais que acabam por se adaptar ao sistema.

Constata-se assim, um elevado nível de insatisfação, frustração, tensão, insegurança, revolta por parte desta população, o que a caracteriza como uma população de alto risco, portanto, sujeita a estados de crise e consequientemente mais vulnerável a desequilíbrios emocionais e psicossomáticos. Uma população "carente" de apoio e orientação e evidentemente em crise de identidade.

Entretanto, é óbvio que uma pequena experiência de livre expressão e comunicação, não é, por si só, suficiente para trazer soluções a curto prazo a estudantes em crise. Soluções, é o que eles mais buscam. Portanto, experiências desta natureza precisam ser sistematicamente repetidas e por sua eficácia são recomendáveis. A riqueza vivencial de experiências como esta, a recomendam como importante recurso auxiliar na compreensão dos problemas que afligem os estudantes de enfermagem.

OLIVEIRA, M. H. P. de et alil Sociodrama with nursing students in Public Health. Rev. Bras. Enf., Brasilia, 37(1): 44-49, 1984.

\section{REFERENCIAS BIBLIOGRAFICAS}

1. D'ANDREA, F. F. Psicodrama com estodiantes de medicina: la crisis de identidad. Educ. Med. Salud, Washington, 5 (3): 221-235, 1971.

2. HINSIE, L. E. \& CAMPBELL, R. J. J. Psichiatry dicionary. 4. ed. New York, Oxford University Press, 1970.

3. MORENO, J. L. Who shall survive? New York, Beacon House, 1953. 